\title{
Otra mirada al rincón de la lexicografía: Cuba
}

\section{Another Look at the Corner of Lexicography: Cuba}

\author{
Ma Ángeles García Aranda [magaranda@filol.ucm.es] \\ Universidad Complutense de Madrid, España
}

\begin{abstract}
RESUMEN
Este trabajo aborda el estudio, contenido, análisis, fuentes y contexto de cuatro nomenclaturas o repertorios temáticos publicados en Cuba durante el siglo XIX. El Vocabulario auxiliar de bolsillo español e inglés de Juan José Romero (Matanzas, 1840), el Arte de hablar bien francés de Pierre Nicolás Chantreau versionado por Pablo Dupuy (La Habana, 1850), El recreo de la juventud de Alfredo Carricaburu (La Habana, 1891) y la anónima Illustrated Guide Book of the Island of Cuba (La Habana, 1893) constituyen un corpus representativo de los materiales que se utilizaron para aprender lenguas extranjeras en la segunda mitad del siglo XIX en Cuba, campo de investigación que cuenta todavía con una trayectoria muy breve.
\end{abstract}

\section{Palabras Clave}

nomenclaturas; Cuba; siglo XIX; español-inglés-francés

\begin{abstract}
This paper presents a study of the content analysis, sources and context of four nomenclatures or thematic lexical repertoires published in Cuba in the nineteenth century. The Vocabulario auxiliar de bolsillo español e inglés of Juan José Romero (Matanzas, 1840), the Arte de hablar bien francés de Pierre Nicolás Chantreau versioned by Pablo Dupuy (La Habana, 1850), El recreo de la juventud of Alfredo Carricaburu (La Habana, 1891) and the Illustrated Guide Book of the Island of Cuba (La Habana, 1893) is a representative corpus of the materials that were used to learn foreign languages in the second half of the nineteenth century in Cuba.
\end{abstract}

\section{KEYWORDS}

nomenclatures; Cuba; nineteenth century; Spanish-English-French

RECIBIDO 2016-09-30; ACEPTADO 2016-12-30

Agradezco a Sara Gómez Seibane la confianza que ha depositado en mí invitándome a participar en este monográfico. Este trabajo se enmarca dentro del Proyecto de Investigación “Biblioteca Virtual de la Filología Española. Fase II. Consolidación, mejora y ampliación de los datos y de la web. Estudio de los materiales contenidos" (FFI2014-5381-P) 


\section{Introducción}

La aparición en 1836 del Diccionario provincial casi razonado de voces y frases cubanas de Esteban Pichardo y Tapia, "el primer diccionario diatópicamente diferencial del español de América" (Werner 1994: 109), sus sucesivas revisiones (1836, 1849, 1862 y 1875) y la publicación en las décadas siguientes de otros diccionarios sobre el español de $\mathrm{Cuba}^{1}$ han acaparado la mayor parte de la bibliografía de la lexicografía cubana (Álvarez Vives 2009; Cárdenas Molina 1999; López Morales 1971; Tristá Pérez 1989).

Pero, como ocurre en otras regiones, junto a estos repertorios más grandes y ambiciosos, la isla de Cuba también conoció otros textos menores que igualmente forman parte de su producción lexicográfica. Entre los textos menores se encuentran las nomenclaturas, ese "rincón de la lexicografía” bautizado en 2013 por Manuel Alvar Ezquerra para referirse a los vocabularios temáticos, a los repertorios léxicos que ordenan sus materiales por ámbitos designativos y que solían aparecer junto a gramáticas o diálogos para facilitar el aprendizaje de una segunda lengua².

Este trabajo aborda el análisis de cuatro de esas nomenclaturas plurilingües, de sus fuentes y del contexto en que fueron compuestas, lo que supone una contribución para la historia de la lexicografía cubana, así como para la historia de los materiales que se utilizaron para aprender lenguas extranjeras en la segunda mitad del siglo XIX en Cuba, campo de investigación que cuenta todavía con una trayectoria muy breve. Por otro lado, estas fuentes lexicográficas atesoran un vocabulario de enorme interés para conocer la situación y la evolución de los americanismos en este periodo, capítulo fascinante de la historia de la lengua española.

\section{Corpus}

El corpus de textos ha sido elaborado - a falta de un catálogo de repertorios lexicográficos del español actualizado- a partir de la consulta de la BICRES IV y V (Esparza y Niederehe 2012 y 2015) y de la Biblioteca Virtual de la Filología Española (www.bvfe.es), y está formado por:

1. Juan José Romero: Vocabulario auxiliar de bolsillo español e inglés. Dividido en tres columnas: la primera en español, compuesta de voces sueltas y diálogos; la segunda, su significación en inglés, y la tercera su más aproximada pronunciación inglesa (Matanzas, 1840).

2. Pierre Nicolás Chantreau (ed. Pablo Dupuy): Arte de hablar bien francés o Gramática completa dividida en tres partes [...] con un suplemento que contiene una nomenclatura muy amplia [...] sacado de los mejores maestros. Última edición muy corregida, revisada y adicionada con todo esmero [...] (La Habana, 1850).

3. Alfredo Carricaburu: El recreo de la juventud. Vocabulario español, inglés y francés (La Habana, 1891).

4. Illustrated Guide Book of the Island of Cuba with an anglo spanish Vocabulary (La Habana, 1893).

1 Por ejemplo, los de José Miguel Macías (Diccionario cubano, etimológico, crítico, razonado y comprensivo, 1888), Constantino Suárez (Vocabulario cubano, 1921) o Fernando Ortiz (Catauro de cubanismos, 1923).

2 Para el concepto y la historia de las nomenclaturas del español véase Alvar Ezquerra (1987 y 2013); Ayala Castro (1992a, 1992b y 1998); García Aranda (2006, 2007 y 2010). 
Cuatro repertorios que compilan el vocabulario español a partir de diferentes ámbitos designativos y que ofrecen su traducción al inglés y al francés - dependiendo del caso-; cuatro nomenclaturas que han corrido diferente suerte entre los investigadores ${ }^{3}$, pero que debieron ser útiles herramientas para el aprendizaje de lenguas extranjeras en un periodo decisivo para la isla de Cuba: la presencia francesa desde la Revolución de Haití a finales del siglo XVIII, las relaciones comerciales, culturales, políticas y económicas con España, los planes de enseñanza ${ }^{4}$ o la creciente influencia americana supusieron el aumento de la edición y publicación de manuales de enseñanza ${ }^{5}$, el incremento de la actividad editorial o la aparición de academias de idiomas (cfr. Sánchez Pérez 1992).

\subsection{El Vocabulario auxiliar de bolsillo español e inglés}

El Vocabulario auxiliar de bolsillo español e inglés. Dividido en tres columnas: la primera en español, compuesta de voces sueltas y diálogos; la segunda, su significación en inglés, y la tercera su más aproximada pronunciación inglesa (Matanzas, Imprenta de Gobierno S.M. y de Marina, 1840) ${ }^{6}$ de Juan José Romero surge, como explica en las páginas introductorias el editor, por

la importancia mercantil que goza la Isla de Cuba: su proximidad al continente americano: sus relaciones cada día mayores con la Gran-Bretaña, de donde deriva la imperiosa necesidad de conocer el enérgico idioma inglés, a lo menos superficialmente, y aunque no sea posible adquirir un profundo conocimiento de él sino a costa de muy largo estudio, son los motivos que me han decidido a emprender esta obra [...]. Notando yo la utilidad que ha de producir la circulación de esta obra en la Isla de Cuba, me he decidido a su reimpresión, purgándola de algunas reglas innecesarias en un tratado de pronunciación, y únicamente útiles en una gramática completa, corrigiendo severamente algunos sonidos equivocados, y enriqueciéndola con diálogos fáciles y variados (p. 3).

Se trata, tal y como consta en la portada, de una versión corregida y aumentada del Vocabulario auxiliar de Barry ${ }^{7}$, que, tras unas páginas dedicadas a las principales nociones de la pronunciación

3 Manuel Alvar Ezquerra (2013) en Las nomenclaturas del español, volumen en el que cataloga más de ciento cincuenta de estos repertorios, incluye el texto de Juan José Romero y parcialmente el de Chantreau (no hace alusión a su continuación americana, solo a sus adaptaciones europeas), pero omite el de Alfredo Carricaburu y la Guía de Cuba.

4 En la segunda mitad del siglo XIX se proclama el Plan de instrucción pública de la Isla de Cuba (1863), adaptación de la ley Moyano (1857), en donde las lenguas vivas habían entrado a formar parte de la enseñanza secundaria como materia obligatoria (Delgado Criado 1994: 505 y ss.).

5 Basta con ver el catálogo de textos gramaticales compuestos en Cuba en el siglo XIX: Antonio José Valdés, Principios generales de la lengua castellana (Habana, 1815?); Esteban de Navea / Juan Claudio Díaz, Elementos de gramática castellana, extractados de los principios de la Real Academia Española (Habana, 18444 ); Braulio Sáenz y José Sixto y Bobadilla, Elementos de gramática castellana (Habana, 1846); Luis de Mata y Araujo, Nuevo epítome de gramática castellana (Habana, 1850); Joaquín Andrés de Dueñas, Tratado de la lengua castellana (Habana, 1855); José Ma de la Torre, Elementos de gramática castellana (Habana, 1856); J. S. y B., Programa de análisis lógico y Sintaxis de la gramática castellana para uso de las clases de $1^{a}$ enseñanza (Habana, 1878); A. Riva de la Torre, Lecciones de gramática castellana (Habana, 1888); Óscar Ugarte, Gramática castellana (Habana, 1893).

6 Utilizo el ejemplar de la Biblioteca Nacional de España con signatura HA/17964, digitalizado en http://bit.ly/2fhi7zg.

7 Sospecha Manuel Alvar (2013: 524-528) que se trate del Auxiliar vocabulario de bolsillo español e inglés de J. José L. Barry. 
inglesa (pues junto a los equivalentes españoles e ingleses aparece la pronunciación figurada de los términos de esta última lengua), recoge el vocabulario del Universo, de la Tierra, del Fuego, de los reinos de Europa y sus capitales, de las cualidades de los cuerpos vivientes, de las partes de que se compone el cuerpo humano, de los oficios, rangos y profesiones, de vestidos de hombres y mujeres, de piedras preciosas, de colores, de estaciones y fiestas del año, de una casa y sus muebles, de los animales, de los árboles y frutas o de las armas y municiones. Después del vocabulario, Romero incluye una tabla para contar con la formación de los números en español, unas "voces usuales y miscelánea de frases familiares" y dos diálogos, uno para informarse de la salud y otro en una oficina de pasaportes.

Como suele ser habitual en estos repertorios, los epígrafes presentan una estructura muy sencilla, con equivalencias simples entre las dos lenguas y sin ninguna información, ni gramatical ni léxica, añadida. Son textos de consulta inmediata, en los que debe primar la sencillez y la utilidad:

\begin{tabular}{|l|l|l|}
\hline \multicolumn{3}{|c|}{ Piezas de que se compone el vestido de hombre (fragmento) } \\
\hline Español & Inglés & Pronunciación \\
\hline un vestido & a suit & e sut \\
\hline casaca & coat & còt \\
\hline chaleco & waistcoat & uestcot \\
\hline calzones & breeches & briches \\
\hline pantalones & pantaloons & pataluns \\
\hline medias & stockings & stókings \\
\hline zapatos & shoes & shus \\
\hline ligas & garters & garters \\
\hline botas & boots & buts \\
\hline botines & leather gaiters & le'dar gueters \\
\hline corbatín & stock & stók \\
\hline corbata & cravat & cravat \\
\hline faltriquera & pocket & póket \\
\hline camisa & shirt & short \\
\hline pañuelo & handkerchief & jándkerchif \\
\hline
\end{tabular}

\subsection{El Arte de hablar bien francés}

En 1850 la imprenta barcelonesa de Francisco Oliva en colaboración con la de Sans de La Habana publica una nueva edición ${ }^{8}$ del Arte de hablar bien francés o Gramática completa dividida en tres partes. Trata la primera de la pronunciación y la ortografía, la segunda de la analogía y el valor de las voces y la tercera de la construcción y sintaxis. Con un suplemento que contiene una nomenclatura muy amplia, las frases más precisas para romper en una conversación, un tratado de la propiedad

8 Además de esta edición con Sans en La Habana, Francisco Oliva sacó a la luz otra más solo en Barcelona en el mismo año. 
de las voces y algunas observaciones del arte de traducir del maestro de francés en la Real Escuela Militar de Ávila Pierre Nicolás Chantreau', editada, en esta ocasión, por Pablo Dupuy.

El "Suplemento" del Arte de Chantreau, originado porque "para hablar una lengua, no basta solamente saber las reglas de la Gramática, sino también es preciso tener en la memoria las voces más usuales en la conversación y trato de la gente”, es una nomenclatura español-francés dividida en tres capítulos: el primero, para los “adjetivos más usuales" pues "con un solo adjetivo se pueden calificar muchos sustantivos, y que por consiguiente importa más saber aquellos antes que estos" (1797: 1); el segundo para los verbos y el tercero para los sustantivos. Los dos últimos ordenan estas categorías gramaticales por ámbitos designativos: hay verbos del estudio, del hablar, del comer y beber, de las acciones de la vida, del vestir, del irse a acostar, del amor y odio, de las acciones naturales al hombre, de las acciones de la memoria y la imaginación, de enfermedades y asistencias, de obras de mano, para la compra y venta o de las acciones que tocan al culto divino; mientras que los sustantivos se agrupan en torno a Dios, a los elementos, al tiempo, a las partes del cuerpo humano, a las cosas pertenecientes del sueño, al alma, a los vestidos, a la mesa, al parentesco, a las dignidades, a las ciencias y artes, al corral de comedias, a los animales, a los metales y minerales, al campo y agricultura, a las medidas, a las monedas o a los instrumentos de música ${ }^{10}$.

Este texto, que apenas tiene diferencias con otros compuestos con anterioridad, se convirtió muy pronto en una obra de referencia para la enseñanza del francés a españoles y fue reeditado y versionado en las centurias siguientes abundantemente: unas veces apareció como Chantreau, otras como Nuevo Chantreau, otras como Novísimo Chantreau y otras como Chantreau reforma$d o$; unas veces con el nombre de los revisores y adaptadores (Hamonière, París, 1815; Núñez de Taboada, París, 1824; Dupuy, Barcelona, 1824; Alemany, Madrid, 1826; Bordas, Barcelona, 1836; Puiggarí, Perpiñán, 1841; Bergnes de las Casas, Barcelona, 1845; Alarcón, Madrid, 1845; Torrecilla, París, 1850; C. Bailly-Baillière, París, 1851; Galbán, París, 1863; Delgado Campos, París, 1875) y otras sin ellos. En cualquier caso,

si se tienen en cuenta las varias o muchas reediciones que cada una de estas versiones del Chantreau tuvieron, así como las numerosas reediciones de la obra que no aparecieron con nombre de revisor, y cuyo listado excusamos, puede uno hacerse una idea más cabal de la presencia masiva de las nomenclaturas en los manuales de francés para hispanohablantes. Sobre todo si, además, se tiene en cuenta que el modelo gozaba de tanto prestigio que se extendió más o menos fielmente a autores que no presentaban sus obras como herederas directas del Chantreau ni de ninguno de sus revisores, pese a que en realidad lo eran (Bruña Cuevas 2008: 76).

Y el éxito del Chantreau fue tal que también se llevó a América. En el inventario del contenido de las librerías que ordenó hacer en 1826 el Capitán General de Cuba Francisco Dionisio Vives constan varios textos lingüísticos franceses: la Gramática de Cormon, la de Tellier, la de Sobrino, el Diccionario de Gattel, el Arte de traducir de Capmany ${ }^{11}$ y el Arte de Chantreau (cfr. Buiguès

9 La primera edición de este texto apareció en Madrid, en la imprenta de Antonio de Sancha, en 1781.

10 Un estudio más detallado sobre el contenido y la estructura de esta nomenclatura puede verse en Alvar Ezquerra (2013: 360-368); Ayala Castro (1992b); Bruña Cuevas (2008); y Carranza Torrejón (2014).

11 Debe referirse a la Gramática francesa de J. L. Barthelemi Cormon (Lyon, 1810), a la versión de Charles-Constant Le Tellier de la Grammaire françoise de Charles Lhomond, "una versión de las múltiples ediciones de la Gramática de Charles 
2011), lo que pone de manifiesto su utilización para aprender francés también al otro lado del Atlántico. Francisco Oliva, miembro de una conocida y veterana saga de impresores catalanes (cfr. Comas i Güell 2009), invirtió en la publicación del Chantreau en Cuba ${ }^{12}$ porque el éxito de ventas estaba asegurado y así garantizaba un centro de distribución en América:

El rápido despacho que ha tenido la Gramática de Chantreau desde que M. Dupuy, profesor de idioma francés, hizo en ella las notables mejoras con que la hemos publicado; el haberla adoptado en la mayor parte de los establecimientos y clases de enseñanza, son una prueba evidente de sus indisputables ventajas [...]. Desde entonces hemos tenido que reimprimirla muchas veces, tal es la acogida que le han dado los maestros de francés y el público. En cada edición hemos puesto nuevo esmero en perfeccionarla ("Advertencia del Editor")

Las ediciones de la nomenclatura de Dupuy financiadas por Francisco Oliva no son muy diferentes de las de Chantreau y, salvo algunas nuevas entradas o modificaciones menores en contados artículos, el repertorio léxico repite epígrafes, repite estructura y repite equivalentes:

\begin{tabular}{|l|l|}
\hline \multicolumn{2}{|c|}{ De una casa y sus partes - D'une maison et de ses parties (fragmento) } \\
\hline Una casa & Une maison \\
\hline Una casa de un grande & Un hotel \\
\hline Un palacio & Un palais \\
\hline Un palacio de campo & Un château \\
\hline Una casa de campo & Une maison de champagne \\
\hline Los cimientos & Les fondemens \\
\hline La pared & La muraille \\
\hline Los muros & Les murs \\
\hline Un rincón o una esquina & Un coin \\
\hline El portal & Le portail \\
\hline El patio & La cour \\
\hline El corral & La base cour \\
\hline Una caballeriza & Une écurie \\
\hline Una cochera & Une remise \\
\hline La escalera & L'escalier \\
\hline Los escalones & Les marches \\
\hline Un piso & Un étage \\
\hline
\end{tabular}

François Lhomond que entre el siglo XVIII y 1825 fue editada más de doscientas veces” (Buiguès 2011: 7), a la Nouvelle Grammaire Espagnolle de Francisco Sobrino (Brusselle, Chez François Foppens. 1697), al Nouveau Dictionnaire espagnol et français, français et espagnol avec l'interprétation latine de chaque mot de Claude Marie Gattel (Lyon, Bruyset, 1790) y al Arte de traducir el idioma francés al castellano de Antonio de Capmany (Madrid, 1776).

12 Un ejemplar de este texto se encuentra en la Biblioteca Museu Víctor Balaguer con signatura SL 12200. 


\subsection{El recreo de la juventud}

En 1891 la Tipografía de los niños huérfanos de La Habana saca a la luz El recreo de la juventud. Vocabulario español, inglés y francés del profesor de inglés y francés Alfredo Carricaburu, quien afirma que se basa "en práctica muy variada [que] habitúa al estudiante a cualquier conversación por difícil que sea; tiene además la ventaja de no usarse el ejercicio fastidioso y lento, siendo, por el contrario, recreativo y rápido, produciendo un resultado sorprendente" o en palabras de sus alumnos "un sistema que hace perder el miedo" (p. 3).

Carricaburu, profesor de lenguas extranjeras, dueño de una Academia de idiomas y director del periódico político independiente consagrado a la defensa de los intereses generales de la raza de color (mayo-julio, 1880) La Fraternidad, fue autor de la colección de poesías inglesas The home companion (1889, Habana, Tipografía de Los Niños Huérfanos), de un Tratado de pronunciación del idioma inglés (1890, Habana, Tipografía de Los Niños Huérfanos) ${ }^{13}$, de una Gramática inglesa compacta (1890, Habana, Tipografía de Los Niños Huérfanos) ${ }^{14}$, de Verbos franceses (1891, Habana, Tipografía de Los Niños Huérfanos) ${ }^{15}$, de Verbos castellanos (1892, Habana, Tipografía de Los Niños Huérfanos), de una Gramática de la lengua castellana explicada con arreglo a un nuevo plan (1893, Habana, Tipografía de Los Niños Huérfanos) ${ }^{16}$ y de Aritmética razonada e ilustrada (1895, s.l., s.n., Habana, La Comercial).

El método que propone Alfredo Carricaburu contiene -como la mayoría de los compuestos en esta centuria- gramática, pronunciación y vocabulario, y tiene su origen, según cuenta su autor en el prólogo de su pronunciación inglesa, en la siguiente reflexión:

13 Tratado que recoge "todas las reglas para la pronunciación de los diferentes sonidos de cada letra; este punto aclarado quedaba otro de no menos importancia, las excepciones. Hay en dicho idioma una infinidad de palabras cuyo sonido se aleja completamente de toda regla, y para reunirlas no escatimé ni paciencia, ni trabajo hasta tenerlas presentadas en sus lugares respectivos"; si bien, y a pesar de las excelencias de la obra, el consejo para "obtener el fruto completo" es "aprender una letra a la vez y las excepciones de memoria" ("A la juventud estudiosa”, p. 3).

14 Contiene según su autor un detallado "sistema muy sencillo y ordenado y justamente en esto estriba su ventaja, pues he colocado las diferentes partes de la oración formando cuadros separados y éstos a su vez los he subdividido en otros tantos cuadros cuanto lo requería el caso; de modo que presento en cada subdivisión de cuadro todas aquellas reglas que tienen relación entre sí, proporcionando por este método el medio de poderlas comparar las unas con las otras. Además he presentado largas listas de palabras, como son los verbos irregulares cuyas irregularidades no se encuentran en todas las gramáticas y una lista de voces españolas con sus diferentes acepciones" (“Del orden brota la claridad”, p. 12).

15 Según las palabras del autor,"un tratado completo que contiene todas las reglas de la gramática con relación a dicha parte de la oración, las que están clasificadas por agrupaciones de modo, que su estudio es muy fácil. También contiene listas de todas las excepciones y la de los verbos irregulares representados en sus cinco tiempos primitivos; se recomienda mucho esta obra por ser de suma utilidad para el estudiante y para el que posee dicho idioma".

16 Las dos obras dedicadas al español, los Verbos castellanos y la Gramática de la lengua castellana explicada con arreglo a un nuevo plan, son textos normativos, en la línea tradicional, "fieles, como la mayoría de las gramáticas cubanas a los preceptos de la RAE", en los que se defiende que la gramática "es el arte de hablar y escribir correctamente o sea conforme al buen uso y a la razón", que "está fundada en reglas" y dividida en cuatro partes "analogía o valor y propiedades de las palabras análogas correspondientes a cada una de las diez partes de la oración tomadas separadamente (artículo, nombre, adjetivo, pronombre, verbo, participio, adverbio, preposición, conjunción, interjección)", "sintaxis o enlace de unos vocablos con otros formando oraciones correctas según las reglas gramaticales", "prosodia o pronunciación de las palabras" y "ortografía o escritura correcta de las palabras".

Frente a estos textos, desde la segunda mitad del siglo XVIII, y gracias a la preponderancia que adquiere en esos momentos la minoría criolla, hay otros que se sitúan en la línea de la gramática filosófica o general y que beben de las nuevas corrientes de pensamiento -desde las tesis empiristas de Bacon y Locke, a las sensualistas de Condillac, pasando por la Ideología de Destutt de Tracy, hasta el Utilitarismo de Bentham y el Positivismo de Comte-. 
Una sola pregunta hago: ¿Cuándo se le enseña al niño su gramática, antes o después que aprenda a hablar? Me dirán: Después - Considerando este plan como el único racional, pues de lo contrario no se consigue otra cosa sino llenar la cabeza del estudiante de reglas confusas, por no tener base positiva; he adoptado un sistema de Evoluciones muy práctico con el cual he conseguido que mis discípulos aprendan en muy corto tiempo, no solamente a conocer las reglas, pero también a leer, traducir, comprender a la viva voz, y a sostener una conversación sobre cualquier tema que sea ("Mi método de enseñanza”, p. 4).

Pese a la escasa originalidad en la concepción y método, estas obras fueron declaradas de utilidad para la enseñanza por la Junta de Instrucción Pública de la isla de Cuba y alabadas por la prensa de la época ${ }^{17}$. Y ello se deba seguramente a que fueron de los primeros métodos de enseñanza de segundas lenguas que se publicaban en la isla de Cuba ${ }^{18}$.

El recreo de la juventud. Vocabulario español, inglés y francés es un pequeño manual (apenas treinta y cinco páginas) que recoge el léxico básico de las tres lenguas en ámbitos designativos y que forma parte del método Carricaburu de enseñanza de lenguas, un método "recreativo y rápido" que produce "un resultado sorprendente". Tanto el título de la obra como las palabras preliminares insisten en la diversión y deleite que conlleva el aprendizaje de lenguas con este nuevo sistema.

El recreo de la juventud recoge en su mayoría sustantivos (para los verbos, como acabamos de ver, había obras específicas) y, en los tres primeros epígrafes, también artículos, pronombres y adjetivos. Los siguientes epígrafes están dedicados a religión, épocas, meses, días, estaciones, el tiempo, división del día, horas, parentesco, estados físicos, el cuerpo humano, los sentidos, defectos corporales y mentales, enfermedades, ropa de hombre, vestidos de mujer, la costura, tocador, joyas, metales, los elementos, partes de una casa, muebles, ropa de casa, utensilios de cocina, comida, animales y números. Llama la atención, sin embargo, la ausencia de otros epígrafes, con una amplia tradición en la lexicografía del español, como la ciudad y sus partes, frutas y verduras, peces y pescados, árboles, la escuela, empleos y profesiones, enfermedades, juegos o colores. Sin duda, Carricaburu, seleccionó materiales y recopiló el léxico que consideró indispensable cumpliendo así las tres propiedades que, según él, debe tener todo libro de enseñanza: claridad, sencillez y orden.

Internamente, el artículo lexicográfico se caracteriza por la sencillez tanto formal como de contenido. La estructura más frecuente que aparece en el repertorio es la aposición: "entrada española + género gramatical + equivalente/s ingleses + equivalente/s franceses + género gramatical". Tan solo los epígrafes sobre el tiempo, los meses, los días, el parentesco y los defectos corporales carecen de género: en el primer caso porque todos los artículos están formados por verbos (impersonales, dice Carricaburu) y en los restantes porque, seguramente, no era necesario: ni los meses, ni los días necesitan de género, en los parentescos están todas las formas femeninas y masculinas en artículos diferentes (padre-madre, hijo-hija, hermano-hermana, abuelo-abuela, nieto-nieta, tío-tía, primo-prima, sobrino-sobrina, suegro-suegra, yerno-nuera,

17 En las páginas preliminares de los textos aparecen escuetas notas de prensa en las que los califican de excelente, notable, indispensable, muy útil, exquisita laboriosidad, utilidad indiscutible, importante trabajo didáctico, verdadera utilidad, felicísimas, didáctico, con resultados admirables, sencillo, original, alcanza grandes adelantos...

18 En esta centuria sí se publicaron gramáticas de la lengua castellana, pero pocos textos bilingües con el español y otra lengua moderna. 
cuñado-cuñada) y en los defectos corporales y mentales, salvo loco, a-mad-fou, folle, solo hay formas masculinas (calvo, tuerto, bizco, ciego, sordo, mudo, tartamudo, jorobado, flaco, cojo, zambo, enfermizo, bobo, enano).

\begin{tabular}{|l|l|l|}
\hline \multicolumn{3}{|c|}{ Muebles - Furniture - Meubles } \\
\hline Mesa, $f$. & Table & Table, $f$. \\
\hline Sillón, $m$. & Arm-chair & Fauteuil, $m$. \\
\hline Mecedor, $m$. & Rocking-chair & Chaise à bascule, $f$. \\
\hline Silla, $f$. & Chair & Chaise, $f$. \\
\hline Sofá, $m$. & Sofa & Sofa, $m$. \\
\hline Piano, $m$. & Piano & Piano, $m$. \\
\hline Taburete, $m$. & Stool & Tabouret, $m$. \\
\hline Espejo, $m$. & Mirror & Miroir, $m$. \\
\hline Cuadro, $m$. & Picture & Tableau, $m$. \\
\hline Lámpara, $f$. & Lamp & Lampe, $f$, \\
\hline Candelero, $m$. & Candle-stick & Chandelier, $f$. \\
\hline Aparador, $m$. & Sideboard & Buffet, $m$. \\
\hline Retrato, $m$. & Portrait & Portrait, $m$. \\
\hline Tapiz, $m$. & Carpet & Tapis, $m$. \\
\hline
\end{tabular}

\subsection{La Illustrated Guide Book of the Island of Cuba}

En 1893 aparece en La Habana la Illustrated Guide Book of the Island of Cuba with an anglo spanish Vocabulary, un "souvernir of Cuba" que, como en los casos anteriores, pretende satisfacer las necesidades lingüísticas de los turistas americanos que visitan la Isla

The principal object of this Guide Book is to give American tourists correct information about interesting places in the island of Cuba, and in particular of the principals cities as Matanzas, Cienfuegos, Cárdenas, etc. The book contains illustrations and maps, and also an Anglo Spanish Vocabulary, all of which we believe, will be of great assistance to Americans travelling in the island of Cuba ("Preface", p. 2)

La Guide Book es un pequeño volumen de apenas ochenta páginas en el que se presenta un resumen de la historia, la geografía, la economía, la religión, la población, el gobierno y las distancias entre Cuba y otras ciudades americanas, así como un breve comentario sobre los hoteles, lugares de interés, hospitales, telégrafos y ferris de La Habana, Matanzas, Cárdenas, Cienfuegos y San Diego de los Baños. De la página cincuenta y dos a la sesenta, antes de una serie de anuncios publicitarios sobre diferentes productos (recuerdos, tabaco, hoteles, tejidos, "underwear inported from Europe", zapatos, abanicos o joyas), se encuentra el "Vocabulary". 
Aparecen a dos columnas una serie de términos y frases para la conversación en inglés y su traducción al español que podrían agruparse en diferentes ámbitos o epígrafes: saludos (buenos días, buenas tardes, buenas noches, señor, señora, ¿cómo está usted?, estoy bien, gracias, adiós), el tiempo (llueve, hace calor, es temprano, es tarde), frases diversas (estoy ocupado, muy bien présteme, estoy listo, tráigame, ¿sabe usted?, haga usted un favor, si usted gusta), parentescos (padre, madre, hermano, hermana), comidas (almuerzo, comida, cena), en el médico (un médico, doctor me siento muy malo, ¿qué tiene usted?, me duele la garganta, siento la boca amarga, ¿tose usted algo?), días de la semana, el correo (¿hay cartas para mí?), en el hotel (¿cómo se llama usted?, ¿hay cuartos desocupados?, ¿cuántos necesita usted?, necesito dos cuartos), prendas de vestir (botas, capa, cuello, guantes, pañuelo, sombrero, zapatos, camisa, sobretodo), con un joyero (¿cuánto vale esta sortija?, reloj de mesa, reloj de bolsa, diamantes, oro, plata, dinero), números, meses del año, comida y bebida (un vaso de leche, huevos pasados por agua, una taza de té, huevos con jamón, un jarro de agua fría, tortilla, sopa de arroz, pescado frito, legumbres, carnero asado, costillas de ternera, riñones a la parrilla, apio, berros, cangrejos, pasteles, naranjas, manzanas, peras).

Se trata, pues, de una recopilación de léxico pensada para un primer acercamiento al español, para resolver los problemas de comunicación que pudieran surgir en los primeros contactos entre los turistas americanos y los habitantes de la Isla. Aunque el valor del texto es muy escaso, demuestra la utilidad y la extensión de este tipo de ordenación en la enseñanza del vocabulario de una lengua extranjera.

\section{El léxico de las nomenclaturas}

Dados los epígrafes y la extensión de las nomenclaturas, es de suponer que apenas tengan interés, por lo básico y elemental, para la historia de la lengua española, pues la mayoría de voces recogidas pertenecen al español general, al conjunto de términos comunes a todos los hispanohablantes. Sin embargo, estos textos, sobre todo a partir de la segunda mitad del siglo XIX ${ }^{19}$, empezaron a reflejar la adaptación del vocabulario a la realidad cubana, por lo que constituyen hoy interesantes corpus para acercarnos, más y mejor, a la historia del léxico americano (Buesa y Enguita 1992; Frago 1999; Moreno de Alba 1992 y 2007; Ramírez Luengo 2015).

\subsection{Lexemas autóctonos de América: papas, boniatos, tomates, zapotes, maíz, loro, caimán, mangos, guayabas y cigarreras}

El equivalente español para potatoes y pomme de terre es en Romero, en Carricaburu y en la Guide Book el americanismo papas (del quechua papa), documentado ampliamente en la historia de la lengua española (h. 1540), usado en América, Canarias y sur de la España peninsular e introducido por los españoles que, ante la nueva realidad, se sirvieron de la voz indígena con que se conocía en América a este tubérculo.

19 El Arte de Dupuy, nueva versión de la nomenclatura de Chantreau, no es interesante en este sentido. Solo el Vocabulario auxiliar de Romero, El recreo de la juventud de Carricaburu y la Guide Book anónima ofrecen información sobre la situación del léxico americano en este periodo. 
El boniato (Carricaburu) o buniato (Guide Book) -traducido como sweet-potato, patate douce-, aunque según Corominas y Pascual (1991) había aparecido en 1537, es raro como sustantivo hasta el siglo XVIII si bien como adjetivo aparece frecuentemente desde comienzos del siglo XVI. La Academia ${ }^{20}$ recoge desde 1869 la forma, pero con una remisión interna a buniato (según Corominas y Pascual 1991, "voz rara y reciente que carece de autoridad”), artículo que no es modificado hasta la edición manual de 1950; antes había aparecido en Salvá (1846) como buniato "batata por la planta y por su bulbo" y en Gaspar y Roig (1853) como "boniato, género de plantas de la familia de las lauríneas que comprende varias especies, todas oriundas de la isla de Cuba”.

Los tomates (tomatoes, del azteca tomatl), los zapotes (sapodillo, del náhuatl tzapotl), el maíz (corn, del taíno mahís), el loro (parrot, del caribe roro) y el caimán (alligator, del taíno kaimán) también cuentan con una amplia documentación desde el siglo XVI.

La voz mango (del tamil mānkāy a través del portugués y del inglés), por su parte, es más tardía y no comienza a aparecer en repertorios lexicográficos hasta comienzos del siglo XVIII (Corominas y Pascual 1991 la datan en 1788). El primero en dar cuenta de ella es Stevens 1706 ("well known in England, brought over in Pickle and an excellent Sauce. The Tree that bears it is large, and thick of Boughs, the Fruit commonly bigger tan a Goose Egg, but in some Parts of India there are of them that weigh above Two Ponds [...]"); tras él Gaspar y Roig 1855 ("nombre vulgar que se da en las Antillas al fruto del mangle") y la Academia en 1884 ("árbol de la familia de las terebentináceas, originario de la India y muy propagado en América, de espeso ramaje, hojas lanceoladas, flores pequeñas, amarillentas y en panoja, y fruto oval, amarillo, de corteza delgada y correosa, aromático y de sabor agradable. || Fruto de este árbol”).

La voz de origen araucano guayaba (guava) se documenta por primera vez, según Corominas y Pascual 1991, hacia 1550, si bien la lexicografía del español no la recoge hasta 1787, en el Diccionario de Terreros y Pando ("fruta de América del grueso de una manzana; el color tira a amarillo, el hollejo y pepitas mui delicado: de modo que todo se come y es mui refrigerante y sabroso; también hacen de la guayaba dulce mui regalado. Fr. Goyave o gouyave") y la Academia en 1803 ("fruta de Indias del tamaño de una manzana mediana y con hollejo como ella, y en su médula algunos granillos o pepitas pequeñas: las hay de varios colores y de distintos sabores").

La primera vez que aparece la voz cigarrera (del maya siyar según la RAE desde 1956; antes: de cigarra por comparación con el cuerpo de este insecto, cigar-case, porte-cigare), "caja o mueblecillo en que se tienen a la vista cigarros puros. Petaca”, en un repertorio lexicográfico es en 1884, en la 12. ${ }^{\text {a }}$ edición del DRAE, apenas unos años antes de la aparición de El Recreo de Carricaburu. Tras él, lo recogen otros lexicógrafos de finales del XIX y principios del XX (Zerolo 1895, Toro y Gómez 1901 o Pagés 1904), así como las siguientes ediciones del diccionario académico (sí hay documentaciones de la forma con el valor de "mujer que hace o vende cigarros").

Esta última forma, según los repertorios lexicográficos y según el CORDE, es habitual a finales del siglo XIX: El espadachín de Antonio Barreras (1880), La Tribuna de Emilia Pardo Bazán (1883) o Tradiciones argentinas de Pastor Servando Obligado (1903, cinco ocurrencias) así lo demuestran. El testimonio de Carricaburu es uno más.

20 Los datos de las diferentes ediciones del Diccionario de la Academia, así como del resto de lexicógrafos que se citan a continuación (Salvá, Gaspar y Roig, Stevens, Terreros, Zerolo, Toro y Gómez, Domínguez...) proceden de los materiales recopilados por la Real Academia Española para el Nuevo Tesoro Lexicográfico del Español. 


\subsection{Lexemas de procedencia española: frazadas, frijoles y chícharos}

Otra de las formas que recoge Carricaburu es frazada (del cat. flassada, vocablo común con la lengua de Oc, origen desconocido), "manta peluda que se echa sobre la cama”, voz más frecuente en España que en América hasta el siglo de Oro, si bien a partir del siglo XVIII se encuentra casi exclusivamente en América (según el CORDE):

\begin{tabular}{|l|c|c|}
\hline Siglos & España & América-Filipinas \\
\hline XVI-XVII $^{\mathrm{a}}$ & 121 & 17 \\
\hline $\mathrm{XVIII}^{\mathrm{b}}$ & 1 & 7 \\
\hline $\mathrm{XIX}^{\mathrm{c}}$ & 4 & 21 \\
\hline $\mathrm{XX}(C O R D E)^{\mathrm{d}}$ & 16 & 157 \\
$\mathrm{XX}(C R E A)^{\mathrm{e}}$ & 10 & 278 \\
\hline
\end{tabular}

a Estas cifras se desglosan así: frazada 23 en España y 9 en América, frazadas 37 en España y 5 en América, frasada 1 en España, fraçada 31 en España y fraçadas 29 en España y 3 en América.

b Estas cifras se desglosan así: frazada 6 en América y frazadas 1 en España y 1 en América.

c Estas cifras se desglosan así: frazada 2 en España y 10 en América, frazadas 1 en España y 11 en América y fraçada 1 en España.

d Estas cifras se desglosan así: frazada 12 en España y 90 en América, frazadas 2 en España y 66 en América, frasadas 2 en España y frasada 1 en América.

e Estas cifras se desglosan así: frazada 4 en España y 142 en América y frazadas 6 en España y 136 en América.

Estas nomenclaturas también muestran la vitalidad en el español de América de dos andalucismos léxicos: frijoles/fríjoles y chícharos. Los primeros, como es sabido, son voces castellanas (del latín faseolus) que en la actualidad son generales en América (donde también se usan las variantes frejol, fréjol y poroto), mientras que en España solo se emplean en algunas regiones, ya que los términos de uso general son judía y alubia.

El DRAE recoge la voz como americanismo, mientras que la variante frijón está clasificada dentro de las formas propias de Andalucía y Extremadura, lo que viene avalado por los corpus de referencia:

\begin{tabular}{|l|l|l|l|l|}
\hline & \multicolumn{2}{|c|}{ España } & \multicolumn{2}{c|}{ América } \\
\hline Frijol - CORDE & ss. XVI-XVII & 0 & ss. XVI-XVII & 3 \\
& s. XVIII & 0 & s. XVIII & 23 \\
s. XIX & 0 & s. XIX & 8 \\
Frijol - CREA & s. XX & 8 & s. XX & 56 \\
\hline
\end{tabular}




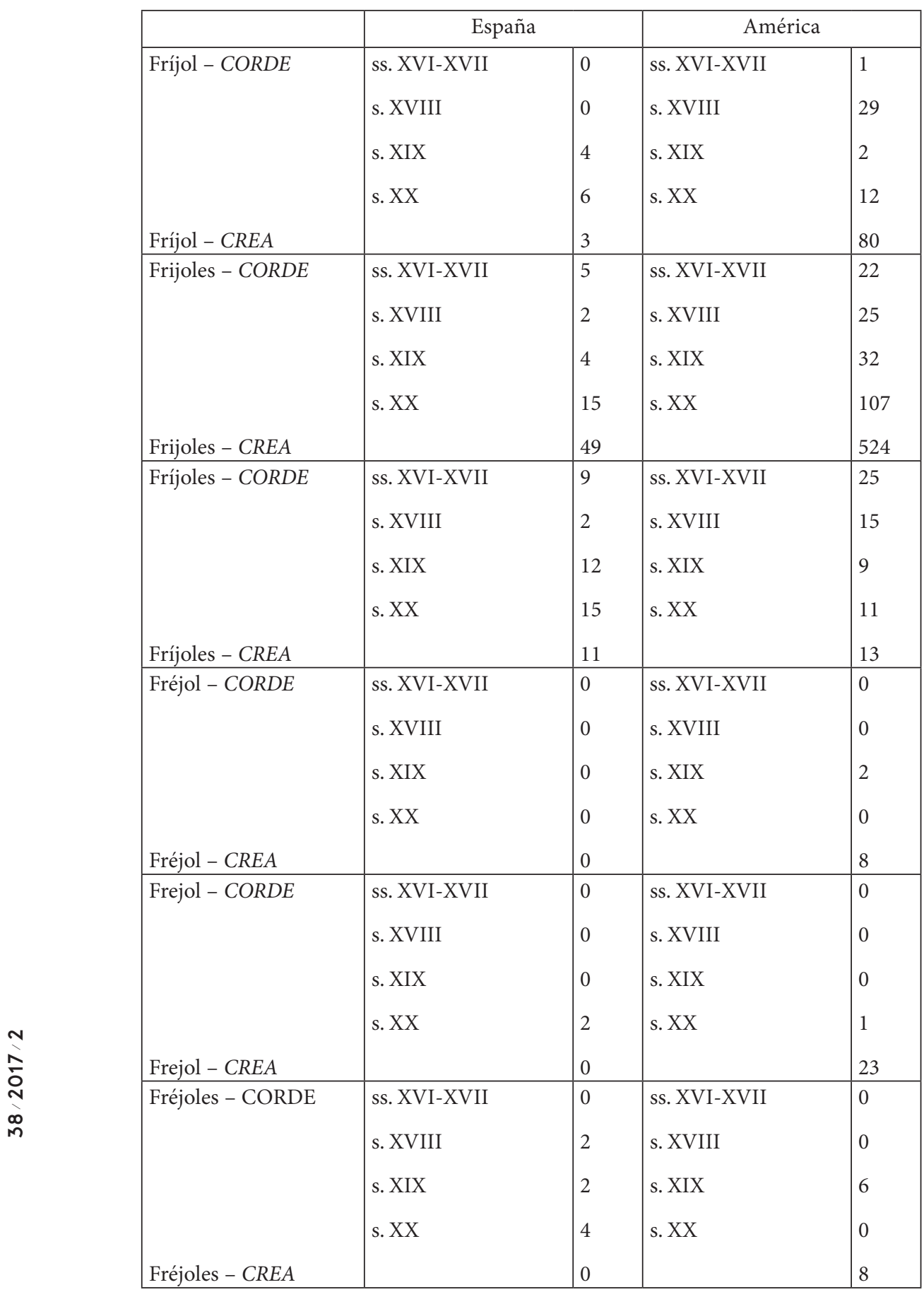




\begin{tabular}{|l|l|l|l|l|}
\hline Frejoles - CORDE & ss. XVI-XVII & 2 & ss. XVI-XVII & 0 \\
& s. XVIII & 0 & s. XVIII & 0 \\
s. XIX & s. XX & 0 & s. XIX & 1 \\
Frejoles - CREA & & 0 & s. XX & 10 \\
\hline
\end{tabular}

\begin{tabular}{|l|l|l|}
\hline Frijón & $2(C O R D E$-s. XX) & 0 \\
\hline
\end{tabular}

Por otro lado, el DRAE afirma que chícharo es (sin marca alguna y con procedencia mozárabe ČÍČAR[O], a su vez del latín CICĚRA) "guisante, garbanzo, judía"; si bien el Diccionario de americanismos (2010) ofrece solo los equivalentes alverja y guisante. En El recreo de la juventud y en la Guide Book se corresponden con "guisante" (es el equivalente del inglés peas y del francés pois), mientras que los garbanzos tienen como equivalentes chisk-peas-pois chiche.

Aunque la voz, según los corpus de referencia, es más usada en América, no faltan datos de su uso en Andalucía: en el ALEA (1961-1973) o en el Tesoro léxico de las hablas andaluzas (2000) se registran chícharos con el valor de guisantes y judías en toda Andalucía.

\begin{tabular}{|l|c|c|}
\hline Siglos & España & América \\
\hline XVI-XVII $^{\mathrm{a}}$ & 0 & 1 \\
\hline XVIII $^{\mathrm{b}}$ & 0 & 3 \\
\hline XIX $^{\mathrm{c}}$ & 2 & 6 \\
\hline $\mathrm{XX}(C O R D E)^{\mathrm{d}}$ & 4 & 125 \\
$\mathrm{XX}(C R E A)^{\mathrm{e}}$ & 5 & 3 \\
\hline
\end{tabular}

a El único caso que recoge el CORDE para este periodo es de la forma chícharos.

b Los tres casos que recoge el CORDE en el siglo XVIII son de la forma chícharos.

c El CORDE recoge dos formas chícharos en España y un chícharo y cinco chícharos en América.

d En el CORDE aparecen un chícharo y tres chícharos en España y dos chícharos y un chicharo en América.

e Las cifras del CREA se desglosan así: 41 chícharo, 83 chícharos y 1 chicharos en América y 5 chícharos en España.

En el DRAE de 1783, primera documentación de la forma, chícharo está marcado como andalucismo ("lo mismo que guisante"); en 1852 desaparece la marca y en 1956 se modifica el artículo de este modo: "chícharo: guisante, garbanzo, judía”.

\subsection{Cambios de género: sartén}

El recreo de la juventud de Carricaburu recoge sartén (frying-pan / poéle à frire) como sustantivo de género masculino, variación genérica que no recoge la Academia hasta la edición manual de 1983, si bien en el CORDE se documentan varios casos anteriores: uno en España en 1944, cuatro en Argentina (dos en 1872, uno en 1931 y otro entre 1954-1967), tres en México en 1955, uno en Cuba entre 1939-1952 y otro en Guatemala en 1867. 
En el Diccionario Panhispánico de Dudas (2005) se dice que “en el habla culta general de España es femenino; su uso en masculino es muy escaso y se restringe al habla popular de algunas regiones. En América, alternan ambos géneros, con predominio del masculino" y en el Diccionario de americanismos (2010) se recoge como masculino en trece países americanos.

\section{4. ¿Arcaísmos?: surcir}

La forma surcir (al parecer derivada de la palabra latina sarcio, is, 'zurcir, recoser, remendar' contaminada con surgo levantar', 'enderezar') hoy según el DRAE desusada, era "lo mismo que zurcir" -ambas formas convivieron durante siglos- en los diccionarios académicos del siglo XVIII, si bien a partir de la edición de 1803 comienza a aparecer con la marca ant. Pese a ello, el CORDE, el CREA y el CORPES documentan varias formas del verbo (surcir, surcía, surcido, surcidos), desde comienzos del siglo XX, pero todas ellas en América (México, Honduras, Perú, Chile y El Salvador) y en textos de muy diferente tipología ${ }^{21}$, datos que podrían hacer pensar en una voz con cierto uso todavía en algunas zonas de América.

\subsection{La adaptación de las voces extranjeras}

Finalmente, el Vocabulario auxiliar, El recreo de la juventud y la Book Guide proporcionan algún dato interesante sobre la incorporación de anglicismos. Recogen estos repertorios tanto puding (El recreo de la juventud) y pudin (Vocabulario auxiliar) como biftec (El recreo de la juventud), adaptaciones de pudding (en francés pouding) y de beef-steak (en francés bisteck), respectivamente. La Guide Book, por su parte, propone el extranjerismo crudo para esta última forma: "broiled steack, beef steak a la parrilla".

La primera forma fue adaptada como budín en 1925 y como pudin (o como pudin a partir de 1985) por la Real Academia en 1927 ("plato de dulce que se prepara con bizcocho o pan desecho en leche y azúcar y frutas secas, cocido todo al baño de María”), si bien estaba ya presente en Salvá (1846), en Domínguez (1853) y en Zerolo (1895). Solo Gaspar y Roig (1855) recoge las variantes pudin o puding. En el Diccionario Panhispánico de Dudas (2005) la Academia da como válidas pudin [púdin], que conserva la acentuación llana etimológica y es la más usada en España, pudín (pl.pudines) y, en especial, la variante budín (pl. budines), generales estas últimas en América. No es admisible la forma puding, que no es ni inglesa ni española.

21 Según el CORDE, el CREA y el CORPES, estos textos se agrupan bajo la siguiente tipología (el subrayado es nuestro):

Los usos de la radio, relatos, México, 1988

Relatos nativos de Arturo Mejía Nieto, relato breve culto, 1929

Discurso de recepción en la Academia chilena de Joaquín Díaz Garcés, oratoria y discurso, Chile, 1918

El segundo libro del trópico de Arturo Ambrogi, novela, El Salvador, 1916

Rivera, Morena: "Nuevas perspectivas". El Diario de Hoy. Hablemos on line. San Salvador: elsalvador.com, 2004-06-12

Huerta, César: "Presentan una cinta sin música". El Universal.com.mx. México D. F.: eluniversal.com.mx, 2008-03-08

Salvatierra, Dany: El síndrome de Berlín. Lima: Estruendomudo, 2012

Luna, Aída: "Chofi". Azul como una ojera de mujer. México D. F.: Editorial Épica, 2008 
La forma biftec es la preferida por la Academia en 1884, si bien la sustituye por bistec en 1925 (“adaptación gráfica de la voz inglesa beefsteak, 'filete de carne de vaca”). Actualmente, la RAE prefiere bistec, aunque da como válida también la forma bisté, reconoce la generalización de bife en la zona del Río de la Plata y desaconseja, por minoritaria, la adaptación biftec.

\section{La originalidad de las nomenclaturas cubanas}

Las nomenclaturas cubanas no son originales en la historia de la lexicografía: la ordenación temática o por ámbitos designativos en la enseñanza del vocabulario se aprovechó en Grecia y Roma para facilitar el aprendizaje del griego, primero, y del latín, después. En el siglo XVI esta ordenación se acomoda a la nueva realidad, pues una serie de circunstancias condicionan las relaciones de las nuevas naciones europeas. La apertura a Europa, el desconocimiento cada vez mayor del latín y la imposibilidad de utilizarlo como lingua franca, el crecimiento de las nuevas tierras extrapeninsulares, el aumento del comercio o la presencia de tropas para mantener la paz en los territorios conquistados modifican considerablemente el objetivo de estos repertorios lexicográficos, pues de ser un instrumento de acercamiento a una lengua muerta pasan a reflejar las necesidades sociales, económicas y políticas de una sociedad que ha cambiado.

Ello explica la aparición, normalmente tras gramáticas y diccionarios de mayor extensión, de pequeños repertorios temáticos ordenados a partir de ámbitos designativos y firmados por los más insignes gramáticos y lexicógrafos áureos (Antonio de Nebrija, William Stepney, Henrich Decimator, Ambrosio de Salazar, Lorenzo de Robles, Alejandro de Luna, César Oudin, Juan de Luna, Lorenzo Franciosini, Stephan Barnabé, Joannes Amos Comenius, Matthias Kramer...; cf. Alvar Ezquerra 2013) y redactados en todas las lenguas conocidas.

Estas ordenaciones siguieron adaptándose y publicándose en las centurias siguientes ${ }^{22}$-de forma independiente muchas veces, con epígrafes dedicados al comercio, a la milicia o a la banca y, en ocasiones, con pronunciaciones figuradas o con ejemplos y modelos de uso- tanto en Europa como en América o Filipinas. En las nuevas tierras, primero se acomodaron a las necesidades de los misioneros y surgieron algunas con el español y una lengua amerindia y después, y debido a los profundos cambios que se producen y a las grandes oportunidades que ofrece América, se utilizan también para la enseñanza del inglés y del francés.

En idéntico contexto, y aprovechando también materiales tradicionales, Romero, Carricaburu y el autor de la Guide Book elaboran sus repertorios.

Las nomenclaturas compuestas en la isla de Cuba evidencian la vitalidad de la ordenación temática a pesar del paso del tiempo, su adaptación a nuevas necesidades y situaciones y su contribución como forma práctica y provechosa para la adquisición del léxico de otras lenguas. Y, gracias a las voces que recopilan, constituyen también interesantes corpus de datos (que pueden

22 Del siglo XVIII son las de François Antoine Pomey, Francisco Sobrino, Félix Antonio de Alvarado, John Andree, John Stevens, Nicolás Vellón, Joaquín de San Pedro, Pietro Tomasi, Pierre Nicolas Chantreau o Felipe Fernández. En la centuria siguiente se compusieron las de Josef de Frutos, John Emmanuel Mordente, Francisco Martínez, Jorge Shipton, Pablo Antonio Novella, Mauricio Bouynot, G. Hamoniére, Luis de Astigarraga y Ugarte, Guillermo de Pinto, Jaime Costa Devall, Luis Bordás, Juan Alarcón, José Luis de Morelle, Agustín Caze, León Chartrou, Darío Julio Caballero, José Torres Reina o Casimir Stryienski, entre otros muchos (cf. Alvar Ezquerra 2013). 
completar y complementar los de los diccionarios alfabéticos) para acercarnos a la historia del léxico americano.

\section{Referencias bibliográficas}

Alvar, M. (1961-1973). Atlas lingüístico y etnográfico de Andalucía. 6 vols. Granada: Universidad de Granada/ CSIC.

Alvar Ezquerra, M. (1987). Apuntes para la historia de las nomenclaturas en español. In Actas del VII Congreso Internacional de Lingüística y Filología de América Latina (ALFAL). Homenaje a Pedro Henríquez Ureña. Santo Domingo, República Dominicana, 1984 (pp.457-470). Santo Domingo: Universidad Nacional Pedro Henríquez Ureña.

- (2000). Tesoro léxico de las hablas andaluzas. Madrid: Arco/Libros.

(2013). Las nomenclaturas del español. Siglos XV-XIX. Madrid: Liceus.

(dir.) Biblioteca Virtual de la Filología Española. <http://www.bvfe.es>

Álvarez Vives, V. (2009). Evolución lexicográfica de las ediciones del Diccionario provincial de voces cubanas de Esteban Pichardo. In L. Romero Aguilera, \& C. Julià Luna (Coords.), Tendencias actuales en la investigación diacrónica de la lengua: actas del VIII Congreso Nacional de la Asociación de Jóvenes Investigadores de Historiografía e Historia de la Lengua Española Barcelona, del 2 al 4 de abril de 2008 (pp. 171-182). Barcelona: Universidad de Barcelona.

Asociación de Academias de la Lengua Española (2010). Diccionario de americanismos. Madrid: Santillana. Ayala Castro, M. C. (1992a). Nomenclatures de l'espagnol (1526-1800). Considérations générales sur la nature et la fonction des nomenclatures. Cahiers de lexicologie, LXI, 127-160.

. (1992b). El concepto de nomenclatura. In M. Alvar Ezquerra (Ed.), Actas del IV Congreso Internacional Euralex'90 (pp. 437-444). Barcelona: Biblograf.

. (1998). Los otros diccionarios del español: clasificaciones metódicas del siglo XIX. In M. Alvar Ezquerra, \& G. Corpas Pastor (Coords.), Diccionarios, frases, palabras (pp. 85-100). Málaga: Servicio de Publicaciones de la Universidad.

Bruña Cuevas, M. (2008). La producción lexicográfica con el español y el francés durante los siglos XVI a XIX. Philologia hispalensis, 22, 37-111.

Buesa Oliver, T., \& Enguita Utrilla, J. M. (1992). Léxico del español de América: Su elemento patrimonial e indígena. Madrid: Mapfre.

Buiguès, J.-M. (2011). Los libros franceses en las librerías de La Habana en 1826. Bulletin hispanique, 113(1), 485-516.

Cárdenas Molina, G. (1999). Apuntes sobre la lexicografía cubana. In M. Aleza Izquierdo (Coord.), Estudios de historia de la lengua española en América y España (pp. 51-56). Valencia: Universidad de Valencia.

Carranza Torrejón, A. M. (2014). La "Recopilación de las voces más usuales para empezar á hablar en francés” (1781) de Pierre-Nicolas Chantreau. Çédille: revista de estudios franceses, 10, 95-114.

Comas i Güell, M. (2009). La imprenta catalana i els seus protagonistas a linici de la societat liberal (18001833). Tesis doctoral.Barcelona:Bellaterra.<http://www.tdx.cat/bitstream/handle/10803/4821/mcg1de1. pdf? sequence $=1>$

Corominas, J., \& Pascual, J. A. (1991). Diccionario crítico etimológico castellano e hispánico. 6 vols. Madrid: Gredos.

Delgado Criado, B. (1994). La educación en la España contemporánea (1789-1975). Madrid: Ediciones SM. 
Esparza Torres, M. Á., \& Niederehe, H.-J. (2012). Bibliografía cronológica de la lingüística, la gramática y la lexicografía del español (BICRES IV). Desde el año 1801 hasta el año 1860. Ámsterdam/Filadelfia: John Benjamins.

- (2015). Bibliografía cronológica de la lingüística, la gramática y la lexicografía del español (BICRES V). Desde el año 1861 hasta el año 1899. Ámsterdam/Filadelfia: John Benjamins.

Frago, J. A. (1999). Historia del español de América. Madrid: Gredos.

García Aranda, Ma Á. (2006). La enseñanza del léxico latino en el Renacimiento: Nebrija, su "Lexicon seu parvum vocabularium" y las nomenclaturas del español. Jaén: Servicio de Publicaciones.

- (2007). La clasificación conceptual del léxico en repertorios españoles de los Siglos XVI y XVII. Revista de Lexicografía, 7, 69-76.

. (2010). Nomenclaturas decimonónicas del español. Boletín de Lingüística, 22, 5-28.

López Morales, H. (1971). Contribución a la historia de la lexicografía en Cuba: observaciones prepichardianas. In H. López Morales, Estudios sobre el español de Cuba (pp. 88-106). Nueva York: Las Américas.

Moreno De Alba, J. G. (1992). Diferencias léxicas entre España y América. Madrid: Mapfre. . (2007). Introducción al español americano. Madrid: Arco/Libros.

Ramírez Luengo, J. L. (2015). El americanismo y la historia: algunas pautas diacrónicas de creación de americanismos (léxicos). Miradas, 13, 114-123.

Real Academia Española (2005). Diccionario Panhispánico de dudas. Madrid: Santillana. . (2014). Diccionario de la lengua española. 23a edición. Madrid: Espasa. <http://dle.rae.es/? $\mathrm{w}=$ diccionario $>$.

[CORDE]: — Corpus diacrónico del español. $<$ http://www.rae.es $>$

[CORPES XXI]: —. Corpus del Español del Siglo XXI (CORPES). <http://www.rae.es >

[CREA]: —. Corpus de referencia del español actual. $<$ http://www.rae.es $>$

[NTLLE]: - Nuevo Tesoro Lexicográfico del español. <http://ntlle.rae.es/ntlle/SrvltGUILoginNtlle>.

Sánchez Pérez, A. (1992). Historia de la enseñanza del español como lengua extranjera. Madrid: SGEL.

Tristá Pérez, A. M. (1989). Breve ojeada a la lexicografía en Cuba. Anuario L/L, 20, 133-140.

Werner, R. (1994). El diccionario de Esteban Pichardo. In J. Lüdtke, \& M. Perl (Coords.), Lengua y cultura en el Caribe hispánico: actas del Congreso de la Asociación de Hispanistas Alemanes celebrado en Augsburgo, 4-7 de marzo de 1993 (pp. 109-130). Tübingen: Niemeyer. 